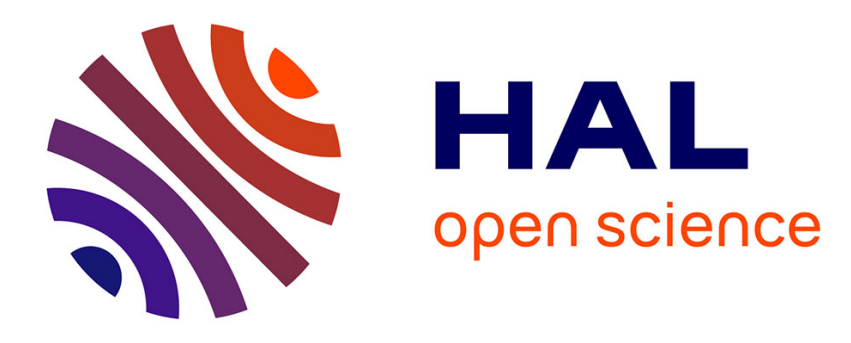

\title{
Grain growth and Ostwald ripening in chromia-doped uranium dioxide
}

\author{
V. Peres, L. Bourgeois, P. Dehaudt
}

\section{To cite this version:}

V. Peres, L. Bourgeois, P. Dehaudt. Grain growth and Ostwald ripening in chromia-doped uranium dioxide. Journal de Physique IV Proceedings, 1993, 03 (C7), pp.C7-1477-C7-1480. 10.1051/jp4:19937231 . jpa-00251868

\section{HAL Id: jpa-00251868 https://hal.science/jpa-00251868}

Submitted on 1 Jan 1993

HAL is a multi-disciplinary open access archive for the deposit and dissemination of scientific research documents, whether they are published or not. The documents may come from teaching and research institutions in France or abroad, or from public or private research centers.
L'archive ouverte pluridisciplinaire HAL, est destinée au dépôt et à la diffusion de documents scientifiques de niveau recherche, publiés ou non, émanant des établissements d'enseignement et de recherche français ou étrangers, des laboratoires publics ou privés. 


\title{
Grain growth and Ostwald ripening in chromia-doped uranium dioxide
}

\author{
V. PERES, L. BOURGEOIS and P. DEHAUDT
}

CEA/CENG DRN/DTP/SECC/LRMC, BP. $85 X, 38041$ Grenoble cedex, France

The use of solid solution additives such as "corundum" types oxides is a practical mean for enhancing grain growth of stoichiometric uranium dioxide. The present paper deals with chromia-doped $\mathrm{UO}_{2}$ samples. Large-grain sized fuels can be produce by addition of less than $1000 \mathrm{ppm}$ of chromia to $\mathrm{UO}_{2}$ powder prior to sintering. Above the solubility limit, excess of insoluble $\mathrm{Cr}_{2} \mathrm{O}_{3}$ precipitates from solid solution to create second phase inclusions in $\mathrm{UO}_{2}$ matrix. These inclusions coalesce by an Ostwald ripening phenomenon.

\section{INTRODUCTION}

A better uranium dioxyde utilization is needed to reduce fission product release from pellets during irradiation. Improvement of fuel performances could be achieved by increasing the diffusion path length of volatile fission products, and dispersing precipitates which are able to pin individual fission gas bubbles in $\mathrm{UO}_{2}$ matrix. Studies have been performed to create new fuel microstructures, mainly characterized by a large grained size, and a dispersion of second phase inclusions.

\section{GRAIN GROWTH}

The use of sintering additives is necessary to promote stoichiometric uranium dioxide grain growth. A recent complete study $[1]$ has been made on $\mathrm{UO}_{2}$ samples doped with "corundum" type oxides showed in table 1 .

Table 1: Solubility limit of different "corundum" structure type oxides in $\mathrm{UO}_{2}$ at $1700^{\circ} \mathrm{C}$.

\begin{tabular}{|cccc|}
\hline OXIDE & Cation radius $(\mathrm{nm})$ & Solubility limit $(\mathrm{ppm})$ & Grain size $(\mu \mathrm{m})$ \\
\hline $\mathrm{Al}_{2} \mathrm{O}_{3}$ & 0,0535 & 70 & 35 \\
$\mathrm{Ti}_{2} \mathrm{O}_{3}$ & 0,0670 & 1000 & 65 \\
$\mathrm{~V}_{2} \mathrm{O}_{3}$ & 0,0640 & 400 & 40 \\
$\mathrm{Cr}_{2} \mathrm{O}_{3}$ & 0,0615 & 700 & 65 \\
\hline
\end{tabular}

In this paper, we will focus on mechanisms reported for chromia-doped uranium dioxide, but these phenomena can be applied to the previously mentionned oxides.

Experimentally, the thermodynamic conditions of the sintered treatments were defined to control the oxidation state of doped cations, to preserve $\mathrm{M}^{3+}$ ions. 


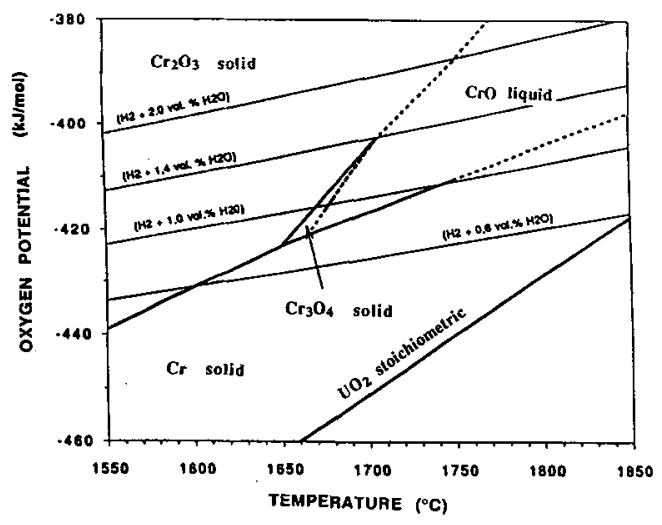

Figure 1: Thermodynamic presentation of chromia-doped $\mathrm{UO}_{2}$ system with some reducting sintering atmospheres [2].

At high temperature, under reducing atmosphere, chromium can be maintained in $\mathrm{Cr}_{2} \mathrm{O}_{3}$ chemical state (figure 1). This favourable condition allows the dissolution of the dopant in the host matrix, and the development of a large grained fuel microstructure.

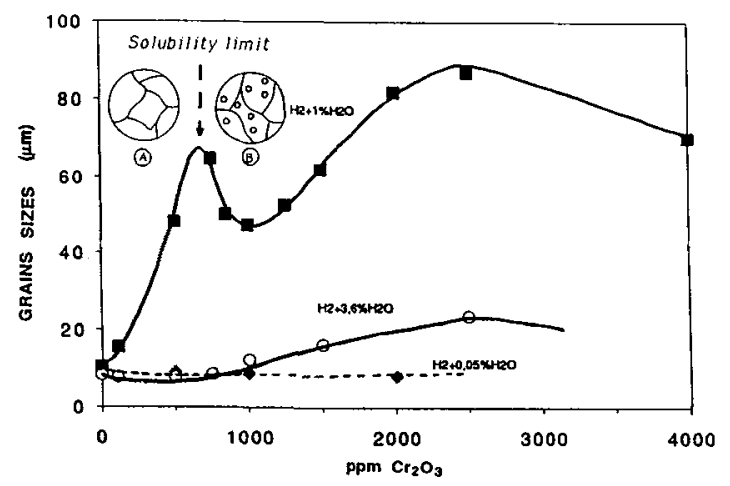

Figure 2: Oxygen potential influence on $\mathrm{Cr}_{2} \mathrm{O}_{3}$-doped samples ( 4 hours at $1700^{\circ} \mathrm{C}$ ).

In figure 2, the grain size of pellets is plotted as a function of initial doped oxide concentration. A solubility limit of additives in $\mathrm{UO}_{2}$ can be found at the upper grain diameter. At $1700^{\circ} \mathrm{C}$, the solubility limit yields $700 \mathrm{ppm}$ for chromia in uranium dioxide.

Two different behaviours must be considered :

- in domain $\mathrm{A}$, for quantity of $\mathrm{Cr}_{2} \mathrm{O}_{3}$ lower than the solubility limit, the dopant oxide is soluble in fluoritic uranium dioxide and forms a substitutional solid solution. It promotes the grain growth. The average maximum grain size reaches $65 \mu \mathrm{m}$. In the same time, an acceleration of specimen densification seems to be influenced by an abnormal grain growth process;

- with an increasing concentration of chromia, above the solubility limit, in domain B, excess of insoluble $\mathrm{Cr}_{2} \mathrm{O}_{3}$ precipitates to form small second phase particles. These inclusions can inhibit grain growth by limiting grain boundaries mobility, such as in a Zener drag type mechanism. When $\mathrm{Cr}_{2} \mathrm{O}_{3}$ concentration increases, the presence of a liquid phase can explain the emphasis of the pellets density and grain growth, showed by the second maximum on figure 2 . At high temperature, Toker and all.[2] propose in a new phases diagram, the existence of an eutectic composition " $\mathrm{CrO}$ " between $\mathrm{Cr}_{2} \mathrm{O}_{3}$ and $\mathrm{Cr}$. The coalescence of large grains takes place by dissolution and diffusion of uranium in the intergranular liquid phase. 


\section{OSTWALD RIPENING}

The chromium oxide micrometric precipitates are almost spherical (figure 3), and located principally within grains.

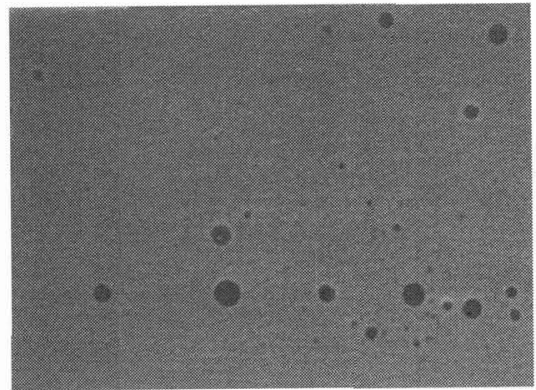

Figure 3: $\mathrm{Cr}_{2} \mathrm{O}_{3}$ precipitates (SEM.BEI X2000)

When heat treatment annealing times reach several hours at $1700^{\circ} \mathrm{C}$, it appears that inclusions coalesce by an Ostwald ripening phenomenon.

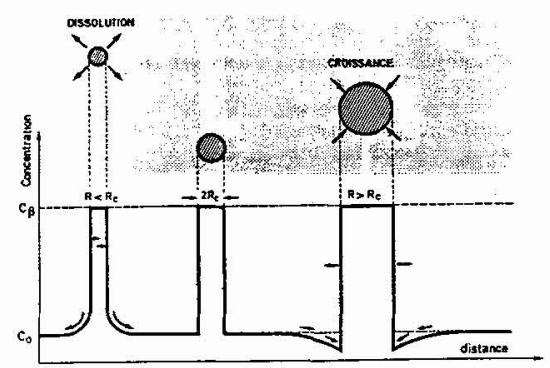

Figure 4: Schematical approach of Ostwald ripening.

The driving force is derived from the consequent reduction in total interfacial energy. The large precipitates grow by diffusion of $\mathrm{Cr}^{3+}$ atoms from small ones through the supersatured host matrix. In the case of chromia-doped samples, with small fraction of second phase noninteracting particles, lower than 1 weight percent, LSW theory [3] can be used. The rate equation is found to be a $1 / 3$ power time law expressed as $G^{3}-G^{3}=K t$; where $G$ is the particle size and $K$ is a constant which depends on $D_{\text {vol }}\left(C^{3} r^{3+}\right)$, the solute $\mathrm{Cr}^{3+}$ volume diffusion coefficient.

Experimental SEM observations of doped pellets, associated with image analysis and then calculations, have been performed to determine the shape of the precipitate size distributions (figure 5) and the diffusion coefficient of $\mathrm{Cr}^{3+}$ (figure 6).

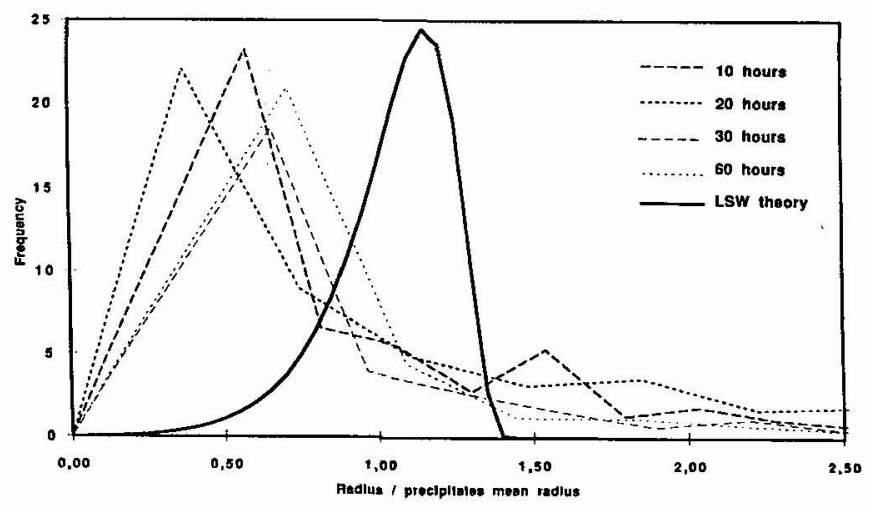

Figure 5: Shapes of the precipitate size distributions, $\mathrm{Cr}_{2} \mathrm{O}_{3}$-doped samples $\left(1700^{\circ} \mathrm{C}\right)$. 


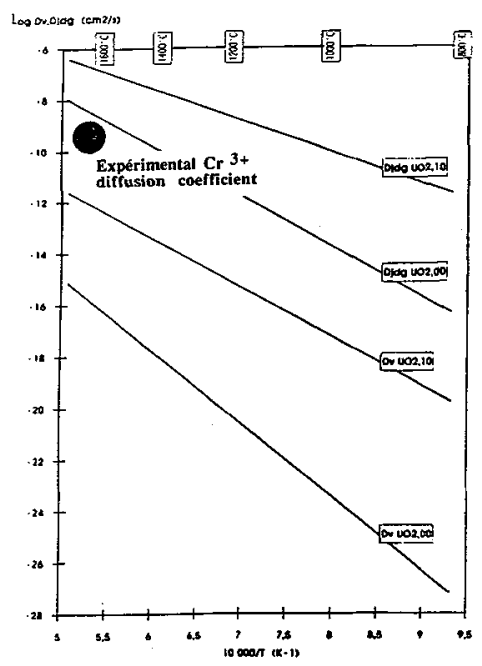

Figure 6: Position of $\mathrm{Cr}^{3+}$ experimental volume diffusion coefficient.

\section{DISCUSSION}

The experimental distributions, stationnary with increasing time, do not agree with the theorical LSW one, based on coarsening of solid precipitates in a liquid or a gazeous medium. These discrepancies were thought to be due to elastic coherency strains and to the presence of grain boundaries short circuit diffusion path. These factors, not included in LSW model, must be considered in polycrystalline solid system.

The $\mathrm{Cr}^{3+}$ volume diffusion coefficient is in the same range value than the uranium grain boundary diffusion coefficient in stoichiometric $\mathrm{UO}_{2}$. However, it is higher by 7 orders of magnitude than uranium volume diffusion coefficient. The value of $\mathrm{D}_{\mathrm{vol}}\left(\mathrm{Cr}^{3+}\right)$ estimated by this original method, is of great interest to predict the irradiation behaviour of chromia-doped fuel.

\section{Acknowledgments}

The authors would like to express their gratitude to A.Hammou and J.F.Baumard for many heppful discussions.

\section{References :}

[1] BOURGEOIS.L., Thesis INPG Grenoble (1992).

[2] TOKER.N.Y, DARKEN.L.S, MUAN.A, Met, Trans. 22B (1991) 225.

[3] YATA.K YAMAGUCHI.T, $J$. Mat. Sciences 27 (1992) 101 